Artigo / Article

\title{
Therapy of chronic myeloid leukemia with imatinib mesylate in Brazil: A study of 98 cases
}

\section{Tratamento da leucemia mielóide crônica com imatinib mesilato no Brasil: estudo de 98 casos}

\author{
Vaneuza A. M. Funke \\ Carlos R. Medeiro \\ Denise H. Lima \\ Daniela C. Setúbal \\ Marco A. Bitencourt \\ Carmem M. Bonfim \\ Jefferson Ruiz \\ José Zanis Neto \\ Ricardo Pasquini.
}

\begin{abstract}
Chronic Myeloid Leukemia (CML) is a clonal disease characterized by balanced translocation between chromosomes 9 and 22 (Philadelphia chromosome). The resulting $B C R-A B L$ gene has tyrosine kinase activity which stimulates cellular growth. Imatinib mesylate is a potent and specific inhibitor of all ABL related kinases. Ninety-eight $C M L$ patients were treated with imatinib mesylate from October 2000 to January 2003. Disease stage was: late chronic phase resistant or intolerant to alpha-interferon $(C P)$ : 28; accelerated phase (AP): 55; blastic phase (BP): 15 patients. Dose: $400 \mathrm{mg}$ for CP and $600 \mathrm{mg}$ for $A P$ or $C B$. The objectives were to evaluation the efficacy, safety and survival with imatinib mesylate therapy in all phases of CML. The median follow up time was 545 days (range: 7-862), complete hematologic response was $86 \%$ in $C P$, $47 \%$ in AP and 13\% in BP. Complete cytogenetic response was $61 \%, 24 \%$ and $0 \%$ respectively. BCR-ABL was not detected by nested RT-PCR in $9 \%$ of patients. Grade 34 hematologic toxicity was seen in $21 \%$ of $C P, 74 \%$ of AP and $87 \%$ of BP patients. Grade 3-4 non-hematologic toxicity was observed in 11\% of CP, $51 \%$ of AP and $53 \%$ of BP patients. Two-year overall survival was $64 \%$ for all patients, $96 \%$ for CP and $36 \%$ for AP patients. All BP patients died within a median of 60 days. Imatinib mesylate induced cytogenetic responses in Brazilian patients with previously treated CML in chronic and accelerated phase. Adverse events are similar to those reported in the literature, except for lower rates of gastrointestinal symptoms and muscle cramps in our study group. Rev. bras. hematol. hemoter. 2005;27(3):159-165.
\end{abstract}

Key words: Chronic myeloid leukemia; imatinib mesylate; major cytogenetic response.

\section{Introduction}

Chronic Myeloid Leukemia (CML) is a clonal disease characterized by the presence of the Philadelphia chromosome, which is a balanced translocation between chromosomes 9 and 22. ${ }^{1,2}$ The resulting hybrid gene BCR$\mathrm{ABL}$ encodes for proteins with tyrosine kinase activity, regulating cellular growth. ${ }^{3}$ Imatinib mesylate is a potent and specific inhibitor of all ABL related kinases, platelet derived growth factor and c-kit. ${ }^{4}$
In imatinib phase II studies, chronic phase (CP) patients previously treated with interferon received imatinib doses of $400 \mathrm{mg}$ /day. Progression free survival was $89 \%$ and $95 \%$ of the patients were alive at the time of analysis. ${ }^{5}$ For accelerated phase (AP) patients, estimated 12-month progression free and overall survival were $59 \%$ and $74 \%$ respectively. Hematologic and cytogenetic responses were higher among patients receiving daily doses of $600 \mathrm{mg} .{ }^{6}$ Hematologic response with imatinib for CML in myeloid and lymphoid blastic phase was $55 \%$ and $70 \%$ respectively. However, all

Institution: Bone Marrow Transplantation Center, HC - UFPR.

Rua General Carneiro, 181

80060-900 - Curitiba-PR - Brazil

Correspondence to: Vaneuza A. M. Funke

Rua da Paz, 412, apt 151 - Centro

80060-160 - Curitiba-PR - Brazil

Tel.: 055413601000 - Fax: 055413601015

E-mail:vaneuza@brturbo.com.br 
lymphoid blast crisis patients relapsed within a median of 58 days, while for myeloid blast crises, a survival rate of $30 \%$ was observed. ${ }^{7,8}$ A prospective randomized study (International Randomized Imatinib Study - IRIS) showed clear superiority for imatinib when compared to interferon and lowdose cytarabine as initial therapy for CML. After a median follow-up of 19 months, estimated rate of major cytogenetic response (MCR) was $87.1 \%$ in the imatinib group and $34.7 \%$ in the interferon group. ${ }^{9}$ In regards to the molecular responses to imatinib mesylate, among 1106 patients from the IRIS study, 370 patients in CCR (complete cytogenetic response) were monitored by real time quantitative PCR. Those who achieved a 3-log reduction from initial BCR-ABL/BCR ratio after 12 months on therapy had a progression free survival of $100 \%$ in 14 months, compared to $95 \%$ for those who not achieved a $3-\log$ reduction but were in CCR and $85 \%$ for those who had not achieved a CCR at 12 months $(\mathrm{p}<0.001) .{ }^{10}$ Imatinib mesylate is a well-tolerated agent. In phase II trials with this drug, grade 3 to 4 hematologic toxicity was seen in $34 \%$ of chronic phase, $58 \%$ of accelerated phase and $63 \%$ of blast phase patients. Non-hematologic toxicity most commonly included nausea (58-71\%), fluid retention (56-71\%), muscle cramps (37-50\%), diarrhea (37-53\%) and skin rash (39-43\%). ${ }^{11}$ However, these adverse events were mostly mild and only rarely resulted in permanent discontinuation of therapy. ${ }^{5.6,7}$

Due to these impressive results and in order to allow the access of the drug to a higher number of patients, patients all over the world were enrolled in expanded access protocols. The present study describes the results of imatinib mesylate therapy for patients included in an expanded access protocol in Curitiba, Brazil, with the objective of evaluating efficacy, tolerance and survival with this drug in our patient population.

\section{Patients and Methods}

Patients or their legal representatives gave informed consent to participate in the clinical study, which was approved by the Institutional Ethics Committee.

\section{Inclusion criteria}

Patients with $\mathrm{Ph}$ positive CML in chronic phase resistant or intolerant to alpha-interferon and patients with accelerated or blastic phase were included in the study.

Resistance to alpha-interferon was defined by the absence of hematologic or cytogenetic response at 6 months of therapy, or failure to achieve a major cytogenetic response after one year of therapy.

Intolerance to alpha-interferon was defined by the development of grade 3 to 4 non-hematologic toxicity for at least two weeks during therapy with this drug.

\section{Exclusion criteria}

Pregnant women; total bilirubin, creatinine, AST and ALT more than twice the normal upper limit, patients with
ECOG $\geq 3$; patients classified as New York Heart Association class grade III or IV; patients who received other chemotherapy agents (except for hydroxyurea) within two weeks from the beginning of the study were excluded.

\section{Therapy}

Chronic phase patients were treated with $400 \mathrm{mg}$ and accelerated or blastic phases patients received $600 \mathrm{mg}$ daily of imatinib mesylate. Medication was given orally, once daily, together with the largest meal of the day. Response evaluation included: weekly complete blood counts, bone marrow aspirate and cytogenetics every six months. Cytogenetic response: partial: $1-35 \% \mathrm{Ph}$; complete: $0 \% \mathrm{Ph}$; minor $36-95 \%$ $\mathrm{Ph}$; no response $>95 \% \mathrm{Ph}$; major: partial + complete. ${ }^{5}$ For patients with complete cytogenetic response, nested RT-PCR was performed to detect the BCR-ABL gene. Quantification of this gene was determined by competitive PCR and results were expressed by BCR-ABL/ABL (\%). NCI/NIH criteria were used to graduate hematologic and non-hematologic toxicity.

\section{Statistical Analysis}

Survival was estimated using the Kaplan-Meyer method. Log-rank test was used to compare survival curves.

\section{Results}

Ninety-eight patients in chronic, accelerated or blastic phase were included at our institution, as part of the STI-571 Brazilian expanded access protocol from October 2000 to January 2003. Patient's characteristics are summarized on Table 1. One patient withdrew his consent, but was included in the intention to treat analysis. Median follow-up was 545 days (range: 7-862).

\section{Imatinib mesylate efficacy}

Chronic Phase: Six patients were intolerant and 22 refractory to alpha-interferon. Among 28 patients, $100 \%$ achieved hematologic response, with 24 (86\%) attaining complete and four (14\%) partial. Median duration of response was 677 days (range: 210-847). Cytogenetics analysis was successfully performed in 25 patients who had adequate number of metaphases for evaluation. Major cytogenetic response (MCR) was seen in $19(68 \%)$ patients, partial in two $(7 \%)$ and complete in $17(61 \%)$. Minor cytogenetic response was seen in one patient (4\%). Five patients (18\%) had no cytogenetic response. Median duration of cytogenetic response was 15 months (range: 6-24). Quantitative RT-PCR for BCR-ABL was performed in 14 out of 17 patients. Median values of the BCR-ABL/ABL ratio at the moment of complete cytogenetic response (CCR), and after three and six months were respectively: 0.38 (range: 0 $11.6 \%$ ); $0.58 \%$ (range: $0-15.4 \%$ ) and $0.06 \%$ (range: $0-5.8 \%$ ). Seven patients were negative for BCR-ABL by nested PCR for BCR-ABL (Figure 1A). 
Table 1

Patient's characteristics

\begin{tabular}{|c|c|c|c|}
\hline & $\mathrm{CP}(\mathrm{N}=28)$ & A $(\mathrm{N}=55)$ & B P $(\mathrm{N}=15)$ \\
\hline Median Age (years) & $49(23-66)$ & $44(10-81)$ & $42(21-70)$ \\
\hline \multicolumn{4}{|l|}{ Sexo } \\
\hline Male & 12 & 33 & 11 \\
\hline Female & 16 & 22 & 4 \\
\hline \multicolumn{4}{|l|}{ Race } \\
\hline Caucasian & 22 & 33 & 9 \\
\hline African & 0 & 1 & 1 \\
\hline Mixed & 6 & 21 & 5 \\
\hline $\begin{array}{c}\text { Splenomegaly }(\mathrm{cm}) \\
>\mathrm{ou}=10\end{array}$ & 0 & 29 & 9 \\
\hline $\begin{array}{l}\text { Leukocytes } \times 10^{9} / \mathrm{L} \\
\text { Median (range) }\end{array}$ & $8.05(3.8-24.4)$ & $17.2(9.0-368.0)$ & $24.5(0.8-156.0)$ \\
\hline Blasts in PB (\%) & & & \\
\hline $\begin{array}{l}\text { Median (range) } \\
>\text { ou }=\text { a } 15\end{array}$ & $\begin{array}{l}0(0-1) \\
0\end{array}$ & $\begin{array}{l}0(0-28) \\
4\end{array}$ & $\begin{array}{l}52(0-76) \\
14\end{array}$ \\
\hline $\begin{array}{c}\text { Basophils in PB (5) } \\
\text { Median (range) } \\
>\text { ou }=\text { a } 20 \%\end{array}$ & $\begin{array}{l}0(0-8) \\
0\end{array}$ & $\begin{array}{l}4(0-36) \\
8\end{array}$ & $\begin{array}{l}4(0-25) \\
2\end{array}$ \\
\hline \multicolumn{4}{|l|}{ Hemoglobin (g/dL) } \\
\hline Median (range) & $13.45(9.7-16.7)$ & $11.65(5.0-16.4)$ & $8.7(5.1-13.0)$ \\
\hline $\begin{array}{l}\text { Platelets } \times 10 \% / \mathrm{L} \\
\text { Median (range) } \\
<100 \times 10 \% \mathrm{~L}\end{array}$ & $\begin{array}{l}270(98-957) \\
1\end{array}$ & $\begin{array}{l}330(13-1,575) \\
11\end{array}$ & $\begin{array}{l}6(4-486) \\
8\end{array}$ \\
\hline $\begin{array}{l}\text { Cytogenetics } \\
\text { Clonal Evolution }\end{array}$ & 3 & 28 & 9 \\
\hline \multicolumn{4}{|l|}{ Previous Therapy } \\
\hline Alpha-interferon & 28 & 28 & 7 \\
\hline Busulfan & 0 & 5 & 2 \\
\hline Bone marrow transplantation & 5 & 5 & 1 \\
\hline $\begin{array}{l}\text { Time from DX to TX (months) } \\
\text { Median (range) }\end{array}$ & $32(11-120)$ & $43(3-120)$ & $24(7-229)$ \\
\hline
\end{tabular}

$\mathrm{PB}=$ peripheral blood; $\mathrm{DX}=$ diagnosis; $\mathrm{TX}=$ theraphy $\mathrm{CP}=$ chronic phase; $\mathrm{AP}=$ accelerated phase $\mathrm{BC}=$ blast crisis
Accelerated phase: Among 55 patients included, 52 patients $(94 \%)$ had hematologic response, with $26(47 \%)$ being complete and 26 (47\%) partial. Three patients $(5 \%)$ had no response. Median duration of hematologic response was 494 days (range: 15-829). Cytogenetic analysis was successfully performed in 42 patients $(76 \%)$. MCR was seen in 18 patients (33\%), with five partial $(9.0 \%)$ and 13 complete $(24 \%)$. Minor response was observed in nine patients (16\%). Sixteen patients $(29 \%)$ had no cytogenetic response. Median duration of cytogenetic response was 13 months (range: 2-24). Quantitative RT- PCR for BCR-ABL was performed in $8 / 13$ patients. Median values of BCR-ABL/ABL ratio at the time of CCR, and after three and six months were: $2.12 \%$ (range: $0-8.7 \%$ ); $0.058 \%$ (range: $0-0.65 \%$ ) and $0.24 \%$ (range: $0-1.16 \%$ ). Two patients (9.1\%) were BCR-ABL negative by nested PCR(Figure 1B).

Blastic phase: Among 15 patients, two achieved CHR (13\%), eight (54\%) partial hematologic response and four $(27 \%)$ had no response. Median duration of hematologic response was 38 days (range: 7-120). Follow-up of cytogenetic analysis was available in four patients $(27 \%)$ at three months of therapy. None had achieved cytogenetic response.

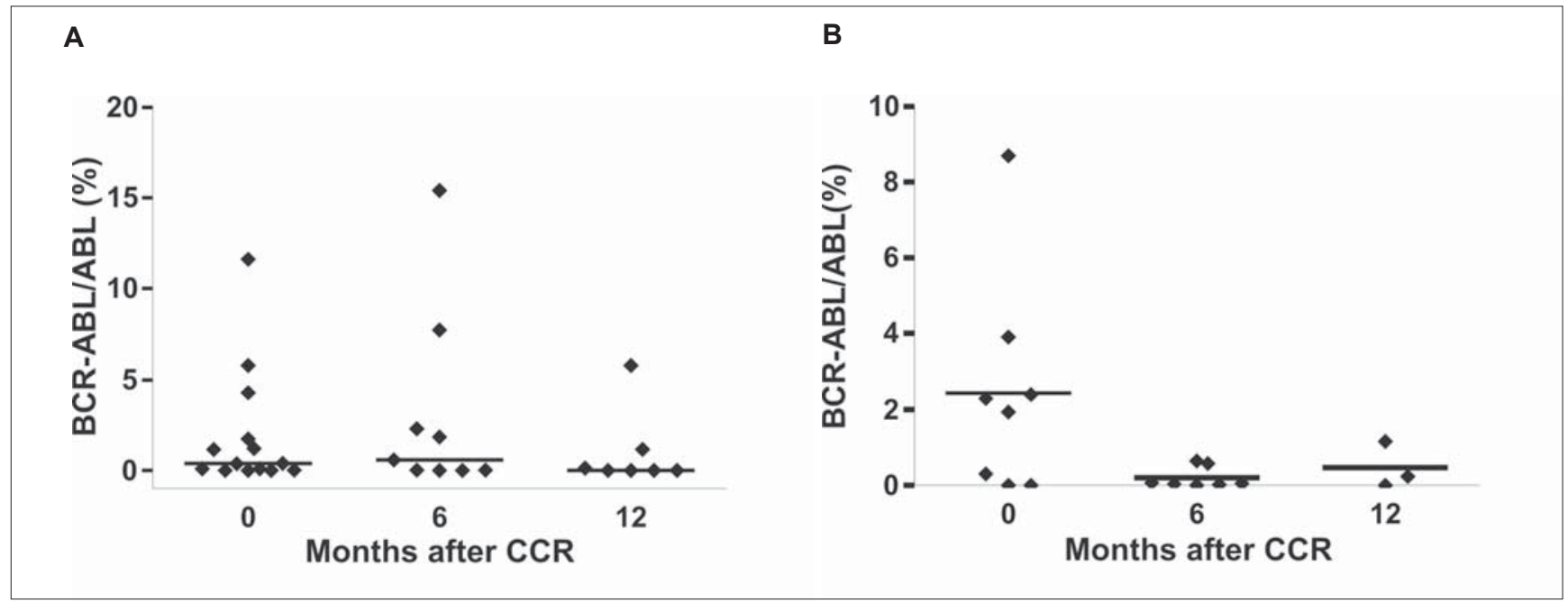

Figure 1. A) Quantitative RT-PCR molecular analysis from Chronic Phase patients in Complete Cytogenetic Response (CCR). Line indicates median. B) Quantitative RT-PCR molecular analysis from Accelerated Phase patients in Complete Cytogenetic Response (CCR). Line indicates median 
Our results of imatinib mesylate efficacy in all phases are summarized on table 2 .

Table 2 Imatinib mesylate efficacy by phase of disease

\begin{tabular}{cccc}
\hline Response & CP (\%) & AP (\%) & AP (\%) \\
\hline & $\mathrm{N}=28$ & $\mathrm{~N}=55$ & $\mathrm{~N}=15$ \\
\hline Hematologic Response & $28(100)$ & $52(94)$ & $66(29)$ \\
Complete & $24(86)$ & $26(47)$ & $2(13)$ \\
Partial & $4(14)$ & $26(47)$ & $8(54)$ \\
No response & $0(0)$ & $3(5)$ & $4(27)$ \\
Not available & $0(0)$ & $0(0)$ & $1(7)$ \\
Cytogenetic Response & $20(72)$ & $25(45)$ & $0(0)$ \\
Complete & $17(61)$ & $13(24)$ & $0(0)$ \\
Partial & $2(7)$ & $5(9)$ & $0(0)$ \\
Minor & $1(4)$ & $9(16)$ & $0(0)$ \\
No response & $5(18)$ & $6(29$ & $4(27)$ \\
Not available & $3(11)$ & $12(22$ & $11(73)$ \\
\hline
\end{tabular}

$\mathrm{CP}=$ chronic phase $; \mathrm{AP}=$ accelerated phase $\mathrm{BP}=$ blastic phase

\section{Survival analysis}

Twenty-seven CP (96.4\%) and $36 \mathrm{AP}(65.4 \%)$ patients are alive at a median follow up of 545 days (range: 7-862). Median survival for CP patients was 684 days (range: 485862) and for AP patients it was 535 days (range: 10-848). Estimated 2-year overall survival was $96 \%$ and $36 \%$, respectively for $\mathrm{CP}$ and AP patients. All BP patients died within a median period of 60 days (range: 15-180) (Figures 2 and 3). Survival was significantly improved for patients who achieved major cytogenetic response (Figure 4).

\section{Imatinib mesylate toxicity}

\section{Hematologic toxicity}

Among the patients in chronic phase, grade 3 to 4 hematologic toxicity was seen in $6(21 \%)$, which is lower than what was observed at the previous reported phase II study. ${ }^{5}$ In AP group, 41 patients (74\%) had grade 3 to 4 hematologic

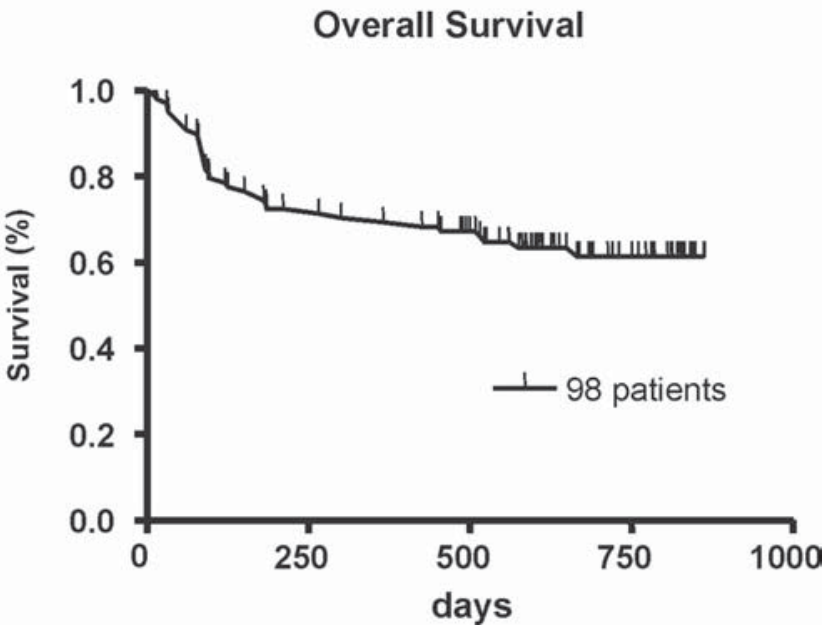

Figure 2. Overall survival of $98 \mathrm{CML}$ patients treated with imatinib toxicity, $28(51 \%)$ of those had severe neutropenia, with a median duration of 14 days (range: 7-150). In BP patients, grade 3 to 4 hematologic toxicity was seen in $12 / 15(80 \%)$. Ten $(67 \%)$ of those had severe neutropenia, with a median duration of 22 days (range: 7-120) (Table 3). For advanced phases, hematologic toxicity rates were not different from those reported in the literature. Imatinib therapy was discontinued due to hematologic toxicity in four CP (14\%), $12 \mathrm{AP}(22 \%)$ and seven BP (47\%) patients. Dose reduction was necessary in four CP, 12 AP and three BP patients. Six patients died from hematologic toxicity complications: five due to neutropenia and infection and one due to cerebral

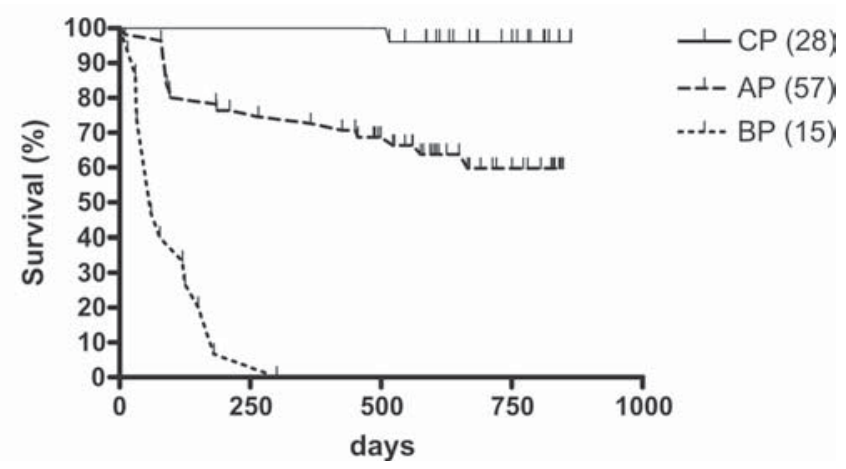

Figure 3. Overall survival by phase of disease. $\mathrm{CP}=$ chronic phase; $\mathrm{AP}=$ accelerated phase $; \mathrm{BP}=$ blastic phase

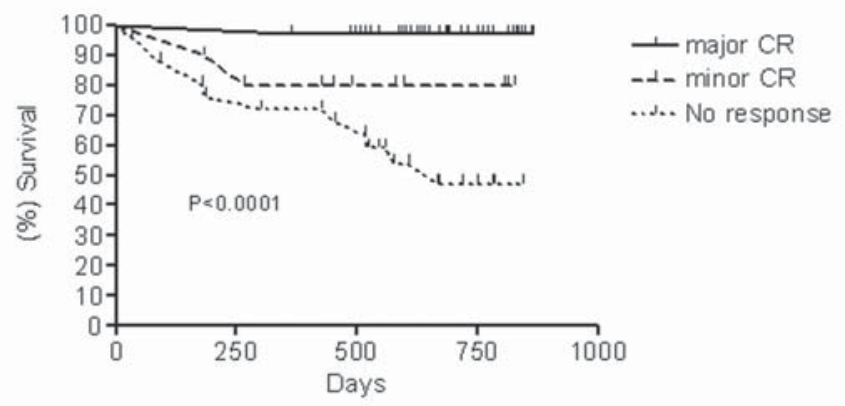

Figure 4. Overall survival by type of cytogenetic response. Major $\mathrm{CR}=$ complete cytogenetic response + partial cytogenetic response

Table 3

Imatinib mesylate hematologic toxicity by phase of disease

\begin{tabular}{cccc}
\hline Myelotoxicity & $\begin{array}{c}\mathrm{CP}(\%) \\
\mathrm{N}=28\end{array}$ & $\begin{array}{c}\mathrm{AP}(\%) \\
\mathrm{N}=55\end{array}$ & $\begin{array}{c}\mathrm{BP}(\%) \\
\mathrm{N}=15\end{array}$ \\
\hline Neuropenia \% & & & \\
Grade 1/2 & $1(4)$ & $0(0)$ & $0(0)$ \\
$\quad$ Grade 3/4 & $5(17)$ & $28(51)$ & $10(67)$ \\
Thrombocytopenia \% & & & \\
Grade 1/2 & $7(25)$ & $7(12)$ & $2(13)$ \\
Grade 3/4 & $3(11)$ & $26(47)$ & $9(60)$ \\
Anemia (g/dL) & & & \\
Grade 1/2 & $7(24)$ & $21(38)$ & $3(20)$ \\
Grade 3/4 & $0(0)$ & $12(22)$ & $9(60)$
\end{tabular}


Table 4

Imatinib mesylate non-hematologic toxicity

\begin{tabular}{ccccc}
\hline & $\begin{array}{c}\mathrm{CP}(\%) \\
\mathrm{N}=28\end{array}$ & $\begin{array}{c}\mathrm{AP}(\%) \\
\mathrm{N}=55\end{array}$ & $\begin{array}{c}\mathrm{BP}(\%) \\
\mathrm{N}=15\end{array}$ & $\begin{array}{c}\text { Total }(\%) \\
\mathrm{N}=98\end{array}$ \\
\hline $\begin{array}{c}\text { Periorbital edema } \\
\text { Lower extremities } \\
\text { edema }\end{array}$ & 1036 & $28(51)$ & $8(53)$ & $46(47)$ \\
Weight increase & 932 & $15(27)$ & $8(53)$ & $32(33)$ \\
Myalgia & $6(21)$ & $8(15)$ & $1(7)$ & $15(15)$ \\
Nausea & $3(11)$ & $8(15)$ & $3(20)$ & $14(14)$ \\
Rash & $297)$ & $8(15)$ & $0(0)$ & $10(10)$ \\
Diarrhea & $2(7)$ & $3(5)$ & $4(27)$ & $9(9)$ \\
Cramps & $6(21)$ & $3(5)$ & $0(0)$ & $9(9)$ \\
Headache & $3(11)$ & $3(5)$ & $0(0)$ & $6(6)$ \\
Hepatotoxicity & $2(7)$ & $2(4)$ & $1(7)$ & $5(5)$ \\
Visual Alteration & $1(4)$ & $3(5)$ & $0(0)$ & $4(4)$ \\
Arthralg & $3(11)$ & $0(0)$ & $0(0)$ & $3(3)$ \\
Deep Venous & $0(0)$ & $1(2)$ & $0(0)$ & $191)$ \\
Thrombosis & $7(13)$ & $0(0)$ & $16)$ \\
\hline
\end{tabular}

$\mathrm{CP}=$ chronic phase $\mathrm{AP}=$ accelerated phase $; \mathrm{BP}=$ blastic phase .

bleeding. All of them had advanced phase disease (AP or $\mathrm{BC})$.

\section{Non-hematologic toxicity}

Grade 3 to 4 non-hematologic toxicity was seen in three out of $28 \mathrm{CP}(11 \%), 28$ out of 55 AP patients (51\%), and in eight out of $15(53 \%)$ BP patients. Grade 1 to 2 nonhematologic toxicity was seen in $18 \mathrm{CP}(64 \%), 23 \mathrm{AP}(42 \%)$ and in $5 \mathrm{BP}(33 \%)$ patients. As can be observed on Table 4, non-hematologic toxicity was similar to previously reported data, except for the lower incidence of nausea (14\%), diarrhea (9\%) and muscle cramps (9\%).

Symptomatic therapy was instituted for GI symptoms (omeprazol, methoclorpramide, anti-diarrheic drugs) with good results. Muscle cramps were managed either by recommendation of soft drinks with quinine content or by prescription of low dose quinine, with improvement in all cases. Most frequent adverse events observed were periorbital (47\%) and extremities edema (33\%), mostly grade 1 or 2 . Patients with moderate to severe lower limb edema were treated with diuretics with good response. A BP patient developed generalized fluid retention syndrome that had no response with diuretics and had to discontinue study drug. Skin rash was observed in $10 \%$ of the patients. If patients presented with severe skin rash, study drug was discontinued and prednisone $1 \mathrm{mg} / \mathrm{kg}$ /day was instituted until resolution of the rash. At this time we restarted the study drug escalating the dose by $100 \mathrm{mg}$ per week. If no rash was seen, prednisone was tapered by $20 \%$ a week. There was no permanent discontinuation of imatinib due to skin rash among our patients. Imatinib was temporarily discontinued due to nonhematologic toxicity in one chronic phase, four accelerated phase and three blast phase patients. We had also some adverse events not previously reported, and therefore causality relationship with study drug remains to be determined. Three patients developed malignant neoplasia during the study. One had a skin carcinoma (treated by surgery), a second had a conjunctivae carcinoma (treated with radiotherapy) and the last one had aggressive colon carcinoma that caused death. One accelerated phase patient developed Graves' disease, of difficult control. She ended up dying from cerebral bleeding and sepsis. Another patient had a hip replacement surgery due to a femur fracture. Curiously, he abruptly developed a large heterotopic calcification around the prosthetic joint. Surgical resection of this osseous tissue was tried twice but bone neoformation came back right after. He finally received local radiotherapy with improvement. Two patients, one in chronic and the other in accelerated phase developed vaginal bleeding not associated with thrombocytopenia. Echography showed endometrial hyperplasia in both cases. Hormonal therapy was instituted with successful control.

\section{Imatinib mesylate as therapy for CML relapse after stem cell transplantation}

Eleven patients received imatinib as therapy for CML relapse after hematopoietic stem cell transplantation (HSCT). Nine patients had previous allogeneic, one syngeneic and one autologous HSCT. From patients who had previous allogeneic HSCT, one relapsed in BP, four in AP and four in CP. Both patients who received previous autologous and syngeneic transplants relapsed in CP. All patients who relapsed after allogeneic transplants received therapy for their relapse with escalated-dose donor lymphocyte infusions, and showed no response after three months from the last infusion. Only patients who relapsed in CP had durable cytogenetic responses. Four of them (including the patient who received a syngeneic transplant) achieved complete cytogenetic response with a median duration of 494 days (range 485-683). One achieved a minor cytogenetic response. In two patients who achieved CCR, BCR-ABL transcripts could not be identified by nested PCR. In all patients with CCR, chimerism analysis by VNTR showed $100 \%$ of donor cells. The patient who relapsed in BP achieved partial hematologic response, but subsequently developed severe neutropenia and died from infection. Among four patients who relapsed in AP, one achieved complete hematologic response and one achieved CCR. However, both of them relapsed at 365 and 465 days of therapy respectively. The two other AP patients had only partial hematologic response and developed progressive disease.

Median duration of hematologic response was 344 days (range 47-639) and median survival was 365 days (90-660). There was no graft-versus-host-disease diagnosed among 
these patients. Seven patients developed hematologic toxicity grade 3-4 with a median duration of 21 days (range 7-120).

The patient who received the autologous HSCT was $\mathrm{Ph}$ negative at diagnosis, and was therefore monitored by quantitative competitive PCR. To this moment, he has progressively lower levels of BCR-ABL/ABL (\%).

\section{Discussion}

Since the earliest clinical studies, imatinib mesylate has progressively demonstrated a major role in therapy of CML, narrowing the indications of bone marrow transplantation. This procedure is the only curative therapy, but is limited to a minority of patients with appropriate age and suitable donors, and it is associated with considerable morbidity and mortality. We conducted this study in an attempt to determine efficacy and safety of imatinib mesylate in our patient population. Some differences emerged, when compared to previous reported STI-571 phase II studies. Median age of our patients at any phase was lower than that observed in previous imatinib studies. ${ }^{5,6,8}$ Some reasons for this may include: shorter life expectancy in our country, compared to developed countries where phase II studies with imatinib took place; expanded access protocols in Brazil were performed in transplant centers, where younger patients are the majority and the fact that in some underdeveloped regions, with limited resources, younger patients are preferentially referred to advanced care centers. Among our $\mathrm{CP}$ patients, good-risk features were more frequently observed at the beginning of therapy median leukocyte count was lower and the median hemoglobin value was higher at the beginning of therapy when compared to previous published phase II studies ${ }^{5}$ (Table1). Accordingly, MCR (68\%) and CCR (61\%) rates were superior and no transcripts were observed by nested PCR in 7 patients, which is more than expected in this group with late disease. When analyzing our AP patients, poor-risk features were less frequently observed in our group. Fifty percent of the patients had spleen size larger than $10 \mathrm{~cm}$ from costal margin, when compared to $26 \%$ of STI-571 109 protocol patients. ${ }^{6}$ Median leukocyte number was lower and only $7 \%$ of our patients had more than $15 \%$ blasts on peripheral blood, while $50 \%$ of patients of STI-571 109 protocol had this characteristic (Table1). We observed that complete hematologic response and CCR rates were 33\% and $24 \%$ respectively, both results superior to those reported in other phase II studies. ${ }^{6}$ Two patients achieved complete molecular response. On the opposite way we seemed to have a worse prognosis in the blast phase group. Seventy-three percent of our patients in this group had spleen size more than $10 \mathrm{~cm}$ from costal margin, compared to $20 \%$ of patients in the STI-571 0102 protocol 8, and median number of peripheral blasts was $30 \%$ in patients from this protocol, compared to $52 \%$ in our study (Table 1 ). None of them have achieved cytogenetic response.
Aforementioned differences in the study population may explain to some extent the different results achieved. Besides, cytogenetics from $25 \%$ of our CP and AP patients could not be evaluated due to insufficient number of metaphases. Most of these patients had pancytopenia that has been associated to poorer responses. ${ }^{12}$ Therefore, many poor responders were not evaluated and this may have contributed to the high percentage of complete cytogenetic responses observed.

The high rate of molecular responses observed in our data must also be confirmed with further evaluation of this group. As we have performed a low number of tests per patient, some might still become positive afterwards. Nevertheless, as expected, nested-PCR negativity was more frequently observed in chronic phase and at the time of complete cytogenetic response (CCR). These preliminary molecular studies suggest that patients on accelerated phase tend to have higher BCR-ABL/ABL ratios when compared to chronic phase patients at the time of CCR. A study using real time-PCR with the objective of evaluating the molecular response to imatinib therapy in all CML phases is in progress at our institution.

In respect to the toxicity profile, $\mathrm{CP}$ patients had lower rates of severe hematologic toxicity (21\%) when compared to protocol STI-571 110 patients, ${ }^{5}$ which correlates well with the good responses achieved. For advanced phases, hematologic toxicity was not different from the literature. Non-hematologic toxicity was similar to previously reported data, except for the lower incidence of nausea, diarrhea and muscle cramps. ${ }^{11}$ One possible explanation for the lower incidence of gastrointestinal symptoms is that our patients were recommended to take the medication at lunch time, as this is the main meal in Brazil. This approach reduced significantly the incidence of those symptoms in our patients during the study. For most patients treated at our institution, a sense of well being and an improved disposition for working were observed. Uncommon adverse events mentioned (malignancies, vaginal bleeding, Graves' disease and heterotopic calcification) were not previously reported and therefore cannot be promptly attributed to imatinib without further evaluation.

The experience with imatinib as therapy for CML relapse after hematopoietic stem cell transplantation is still limited. Kantarjian et al published their experience in 28 patients who received imatinib after allogeneic HSCT. Five patients were in CP, 15 in AP and 8 in BP. Hematologic response was observed in $74 \%$ and cytogenetic response in $58 \%$ of the patients. Nine patients (35\%) achieved CCR. After a median follow-up of 15 months, 19 patients were alive, 9 with no evidence of disease. The one-year estimated overall survival was $74 \%$. Five patients developed graft-versus-host-disease and severe neutropenia and thrombocytopenia were observed in $43 \%$ and $27 \%$ of the patients respectively. ${ }^{14}$ In our study, only those patients who relapsed in CP had durable cytogenetic responses. In all complete cytogenetic 
responders, VNTR analysis showed $100 \%$ of donor cells. Hematologic toxicity grade 3 to 4 was observed in $77 \%$ of the patients in our group, and no garft-versus-host-disease was observed.

We conclude that imatinib mesylate demonstrated high efficacy and tolerability in Brazilian CML patients in the CP. Further studies with this drug alone or combined to either bone marrow transplantation or other agents are necessary to improve results for advanced phase patients. As data from the IRIS trial showed better responses for patients who received imatinib as frontline therapy, this drug has been set as the new gold-standard therapy for CML in the CP all over the world. ${ }^{9,13}$ Although indication of imatinib as first line therapy for CML patients is already approved in Brazil by ANVISA (Agência Nacional de Vigilância Sanitária), it has still not received financial support from our Public Health System (Sistema Único de Saúde - SUS). As a revised version of the current law is under evaluation, we do hope that Brazilian patients with CML who depend on Public Health support will soon have also the right to receive this therapy in its best indication.

\section{Resumo}

Introdução: A Leucemia Mielóide Crônica (LMC) é uma doença clonal caracterizada pela presença da translocação entre os cromossomos 9 e 22 (cromossomo Philadelphia). O gene resultante BCR-ABL possui atividade de tirosino-quinase, que estimula o crescimento celular. O mesilato de imatinibe é um inibidor potente e especifico de todas as quinases relacionadas ao ABL. Pacientes e Métodos: Noventa e oito pacientes com LMC foram tratados com mesilato de imatinibe de outubro de 2000 a janeiro de 2003: $28 \mathrm{em}$ fase crônica ( $F C$ ) resistente ou intolerante ao interferon alfa; $55 \mathrm{em}$ fase acelerada (FA) e 55 em crise blástica (CB). Dose: $400 \mathrm{mg}$ para CP e 600 mg para FA ou CB. Objetivos: Avaliação da eficácia, segurança e sobrevida após tratamento da LMC com mesilato de imatinibe. Resultados: Seguimento mediano: 545 dias (variação: 7-862). Resposta hematológica completa ocorreu em $86 \%$ dos pacientes em FC, 47\% na FA e 13\% na CB. Sessenta e um por cento, $24 \%$ e $0 \%$ dos pacientes em FC, FA e CB, atingiram resposta citogenética completa, respectivamente. Não foram detectados transcritos BCR-ABL por "nested RT-PCR" em 9\% dos pacientes. Toxicidade hematológica grau 3-4: 21\% na FC, 74\% na FA e em 87\% na CB. Toxicidade não hematológica grau 3-4: $11 \%$ na FC, $51 \%$ na FA e 53\% na CB. A sobrevida global em dois anos foi de $64 \%$ para todos os pacientes, $96 \%$ na FC e $36 \%$ na FA. Todos os pacientes em CB faleceram numa mediana de 60 dias. Conclusões: O mesilato de imatinibe induziu respostas citogenéticas completas em pacientes brasileiros com LMC em fase crônica e acelerada. Os eventos adversos nos nossos pacientes foram semelhantes aos relatados em literatura, exceto pela menor incidência de sintomas gastro-intestinais e câimbras. Rev. bras. hematol. hemoter. 2005; 27(3):159-165.

Palavras-chave: Leucemia mielóide crônica; Imatinibe mesilato; resposta citogenética maior.
Acknowledgement

Heliz R. A. das Neves. (Statistician)

\section{References}

1. Sawyers CL. Chronic Myeloid Leukemia. New England Journal of Medicine 1999;340(17):1.330-1.340.

2. Thijsen SFT, Schurhuis GJ, van Oostveen JW et al. Chronic myeloid leukemia from basics to bedside. Leukemia 1999;13(11):1.6461.674 .

3. Faderl S, Talpaz M, Estrov Z et al. The biology of chronic myelogenous leukemia. New England Journal of Medicine 1999; 341(3):164-172.

4. Savage DG \& Antman KH. Imatinib mesylate - a new oral targeted therapy. New England Journal of Medicine 2002;346 (9):683-691.

5. Kantarjian HM, Sawyers C, Hochhaus A et al. Hematologic and cytogenetic responses to imatinib mesylate in chronic myelogenous leukemia. New England Journal of Medicine 2002;346(9):645-652.

6. Talpaz M, Silver RT, Druker BJ et al. Imatinib induces durable hematologic and cytogenetic responses in patients with accelerated phase chronic myeloid leukemia: results of a phase 2 study. Blood 2002;99(6):1.928-1.937.

7. Druker BJ, Sawyers CL, Kantarjian H et al. Activity of a specific inhibitor of the BCR-ABL tyrosine kinase in the blast crisis of chronic myeloid leukemia and acute lymphoblastic leukemia with the Philadelphia chromosome. New England Journal of Medicine 2001;344(14):1.038-1.042.

8. Sawyers CL, Hochhaus A, Feldman E et al. Imatinib induces hematologic and cytogenetics responses in patients with chronic myelogenous leukemia in myeloid blast crisis: results of a phase II study. Blood 2002;99(10):3.530-3.539.

9. O'Brien SG et al. Imatinib compared with interferon and low dose cytarabine for newly diagnosed chronic phase chronic myeloid leukemia. New England Journal of Medicine 2003;348(11):9941004 .

10. Hughes TP, Kaeda J, Branford S et al. Frequency of major molecular responses to imatinib or alpha-interferon plus cytarabine in newly diagnosed chronic myeloid leukemia. New England Journal of Medicine 2004;349(15):1.423-1.432.

11. Deininger MWN, O'Brien SG, Ford JM et al. Practical management of patients with chronic myeloid leukemia receiving imatinib. Journal of Clinical Oncology 2003;21(8):1-11.

12. Jiang Q, Chen S, Jiang B et al. Relationship between cytopenia and cytogenetic response in imatinib mesylate treated $\mathrm{Ph}$-positive chronic myeloid leukemia in chronic phase patients. Beijing Da Xue Xue Bao 2003;35(2):136-140.

13. Peggs K, Mackinnon S. Imatinib mesylate - the new gold standard for treatment of chronic myeloid leukemia. New England Journal of Medicine 2003;348(11):1.048-1.050.

14. Kantarjian HM, O'Brien S, Cortes JE et al. Imatinib mesylate therapy for relapse after allogeneic stem cell transplantation for chronic myelogenous leukemia. Blood 2002;100(5):1.590-1.595.

Avaliação: Editor e dois revisores externos.

Conflito de interesse: Novartis Pharma forneceu os medicamentos para o estudo

Recebido: 10/07/2005

Aceito após modificações: 14/09/2005 